\title{
Colorectal Cancer in Inflammatory Bowel Disease
}

\author{
Ryan W. Stidham, MD, MSc ${ }^{1}$ Peter D.R. Higgins, MD, PhD, $\mathrm{MSc}^{1}$ \\ ${ }^{1}$ Division of Gastroenterology and Hepatology, Department of \\ Internal Medicine, University of Michigan, Ann Arbor, Michigan \\ Clin Colon Rectal Surg 2018;31:168-178. \\ Address for correspondence Ryan W. Stidham, MD, MSc, \\ Department of Internal Medicine, University of Michigan, 1500 East \\ Medical Center Drive, 3912 Taubman Center, Ann Arbor, MI 48109 \\ (e-mail: ryanstid@med.umich.edu).
}

\begin{abstract}
Patients with inflammatory bowel disease (IBD) are at significantly increased risk of colorectal cancer (CRC), principally resulting from the pro-neoplastic effects of chronic intestinal inflammation. Epidemiologic studies continue to highlight the increased risk of CRC in IBD. However, the incidence has declined over the past 30 years, attributed to both successful CRC-surveillance programs and improved control of mucosal inflammation. Risk factors that further increase the risk of IBD-related CRC include disease duration, extent and severity, the presence of inflammatory pseudopolyps, coexistent primary sclerosing cholangitis, and a family history of CRC. All major professional societies agree that IBD-CRC surveillance should occur more frequently than in the general population. Yet, guidelines and consensus statements differ on the surveillance schedule and preferred method of surveillance. Improved sensitivity to previously "invisible" flat dysplastic lesions using high definition and chromoendoscopy methods

\section{Keywords}

- inflammatory bowel disease

- Crohn's disease

- ulcerative colitis

- colorectal cancer

- dysplasia

- chromoendoscopy

- chemoprevention has resulted in many guidelines abandoning requirements for random untargeted biopsies of the colon. While colonic dysplasia remains a worrisome finding, and several clinical scenarios remain best addressed by total proctocolectomy due to concerns of synchronous undetected lesions and the unpredictable tempo of progression to malignancy, better detection techniques have also increased opportunities for endoscopic resection of dysplastic lesions that can be clearly delineated. Finally, the expanding armamentarium of medical options in IBD, including anti-tumor necrosis factor and anti-adhesion biologic therapies, have substantially improved our ability to control severe inflammation and likely reduce the risk of CRC over time.
\end{abstract}

\section{Epidemiology of CRC in IBD}

Colorectal cancer (CRC) is a major cause of death in both ulcerative colitis (UC) and colonic Crohn's disease (CD), accounting for 10 to $15 \%$ of all-cause mortality in inflammatory bowel disease (IBD). ${ }^{1}$ The chronic or repeated episodic inflammatory insults to the intestinal mucosa have a clear mechanistic role in the development of IBD-related CRC. The association between IBD and CRC has driven recommendations for greater intensity surveillance programs in both
North America and Europe. Despite its clear impact, more recent epidemiologic studies suggest a lower incidence of IBD-related CRC than historically reported. The association between CRC and IBD was first suggested by Burrill Crohn and Herman Rosenberg in 1925. By 1971, a landmark population-based study in the United Kingdom identified UC patients as having a $5 \%$, and later a $40 \%$, prevalence of CRC after 10 and 25 years of disease, respectively. ${ }^{2}$ Dozens of additional studies were undertaken over the subsequent 30 years to refine the prevalence of CRC in IBD. Synthesizing the
Issue Theme Translational Research in Colorectal Cancer; Guest Editor: Karin M. Hardiman, MD, PhD
Copyright $\odot 2018$ by Thieme Medical Publishers, Inc., 333 Seventh Avenue, New York, NY 10001, USA. Tel: +1(212) 584-4662.
DOI https://doi.org/ 10.1055/s-0037-1602237. ISSN 1531-0043. 
results of 116 studies of IBD-related CRC in 54,478 patients between 1966 and 1999, the 2001 meta-analysis by Eaden and colleagues reported an overall CRC prevalence of $3.7 \%$ among UC patients. ${ }^{3}$ When stratified by disease duration, the study of Eaden and colleagues revealed a cumulative risk of CRC of $2 \%$ after 10 years, $8 \%$ at 20 years, and $18 \%$ at 30 years. These results were corroborated by national registry studies performed within similar time periods. Bernstein and colleagues reported that UC conferred a relative risk for CRC of 2.75 (95\% confidence interval [CI]: 1.91-3.97) when compared with a matched-population cohort of 2,672 subjects in Canada. ${ }^{4}$ In tandem with the introduction of colonoscopy as the standard method for CRC screening, these studies constituted the evidence-based foundation guiding our modern IBD surveillance schedules.

While the increased risk of CRC conferred by IBD is unquestioned, more recent studies suggest that the prevalence of CRC is declining and may have been overestimated by studies in tertiary care centers. A Swedish registry study of 7,607 patients between 1954 and 1989 found a twofold increased relative risk of CRC in IBD compared with the nonIBD background population (standardized incidence ratio [SIR]: 2.7, 95\% CI: 2.3-3.2). ${ }^{5}$ Analysis of the CESAME (Cancer et Surrisque Associé aux Maladies Inflammatoires Intestinales En France) prospective observational cohort identified a twofold increased risk of CRC in both UC and CD. ${ }^{6}$ When stratifying by extent and duration, those with longstanding pancolitis, representing the bulk of the risk, exhibited a SIR of 7.0 (95\% CI: 4.4-10.5). However, in contrast to the data presented, numerous studies have detected no additional risk of CRC in IBD. A 2006 study examining the Olmsted County population health registry (United States), though only including 378 IBD patients, found no significant difference in the SIR of CRC in IBD compared with the general population (SIR: 1.1, 95\% CI: 0.3-2.4). ${ }^{7}$ Using the Danish National Patient Register, Jess and colleagues reviewed CRC outcomes in a nationwide cohort of 47,374 patients with IBD between 1979 and 2008 and found the overall risk of CRC comparable to the general population on analysis adjusted for age and year of CRC diagnosis (relative risk [RR]: 1.07; 95\% CI: $0.95-1.21),{ }^{8}$ which may be influenced by a high rate of colectomy for IBD in Denmark. A subsequent study using the same Danish national cohort found that over two decades, incidence (RR: 0.59, 95\% Cl: 0.39-0.90) and mortality (hazard ratio [HR]: $0.69,95 \% \mathrm{CI}: 0.49-0.98$ ) of CRC in UC have both declined between the 1982-1989 and 2000-2010 time periods. $^{9}$

The apparent reduction in CRC risk over time has been attributed to both improvements in clinical data quality, study design, and analysis, as well as advances in modern disease management. Older studies often failed to control for disease severity, medication use, and other covariates that impact the incidence, extent, and mortality from CRC in IBD. ${ }^{10}$ In addition, the case-control studies using patients from tertiary care and academic centers appear to significantly influence the CRC incidence compared with population-based studies that include community medical centers. ${ }^{11}$ When restricting population-based datasets to referral centers, the IBD-related CRC SIR was 6.9 (95\% CI: 4.1-9.7) compared with an SIR of 1.7 (95\% CI: 1.3-2.1) in the general population. ${ }^{12} \mathrm{~A}$ meta-analysis using exclusively population-based studies from the United States, Canada, and Europe found that over 14 years of follow-up, $1.6 \%$ of patients with UC developed CRC, corresponding to a 2.4-fold increase risk of CRC compared with baseline $(95 \% \mathrm{CI}$ : 2.1-2.7). In this meta-analysis, the absolute cumulative risk of CRC in UC was $1.15 \%$ after 15 years, $1.69 \%$ after 20 years, and $2.61 \%$ after 25 years, ${ }^{13}$ much lower than older reports. Secular changes in disease management also contribute to the apparent reduction of IBD-related CRC risk. ${ }^{14}$ The introduction of chronic maintenance therapy to suppress subclinical inflammation using 5-ASA, immunomodulators, anti-tumor necrosis factor (anti-TNF), and now anti-integrin therapies may be reducing the incidence of CRC. Further, the seminal studies from the 1990s and early 2000s highlighting the risk of CRC in IBD fostered enhanced surveillance programs detecting dysplasia prior to cancer development, as well as cancers at an earlier stage. Finally, improved understanding of the biology, behavior, and natural history of IBD-related dysplasia has provided guidance for preventative colectomy.

\section{The Risk of CRC Specific to Patients with Crohn's Disease}

The risk of CRC in CD is less well studied than in UC, with prevalence estimates varying from a RR of 0.80 to greater than 20 in the studies presented previously. As in UC, the risk of CRC in CD appears to be greater in referral center cohorts, although population-based studies have also demonstrated an increased CRC occurrence in CD. Unsurprisingly, risk factors of CRC in CD include a colonic disease distribution, which has been reported to confer a CRC relative risk of 4.5 (95\% CI: 1.3-14.9); ileocecal and isolated ileal disease was not associated with an increased risk of CRC. ${ }^{15}$ Administrative claims data from the Kaiser-Permanente Health Care System (USA) between 1998 and 2010 reported a 1.6-fold significant increase in CRC in patients with colonic distribution $\mathrm{CD}$, but not ileocecal or ileal disease. ${ }^{16}$ Studies have not defined the threshold length or severity of colonic involvement required to increase the risk of CRC. At our center, we typically perform IBD-CRC surveillance when one-third or more of the colon is involved. Beyond the length of colonic inflammation, a history of focal severe inflammation resulting in pseudopolyposis, visible scarring, or colonic stricturing disease, even in an area less than one-third the colon length, is a sufficient indication for CRC surveillance in CD patients. $^{10,17}$

\section{Risk Factors for IBD-Related CRC}

Several factors modifying the risk of IBD-related CRC have been identified ( - Table 1). The age at IBD diagnosis was a key risk factor for CRC compared with background population, as those diagnosed at age 0 to 19 had a RR of 43.8 (95\% CI: 27.2-70.7) compared with those diagnosed at age 20 
Table 1 Summary of risk factors for colorectal cancer in IBD

\begin{tabular}{|c|c|c|c|}
\hline Risk factor & Risk of CRC & Study design & Reference \\
\hline \multicolumn{4}{|l|}{ Disease duration } \\
\hline Annual incidence & $0.06-0.20 \%$ & Meta-analyses & 14 \\
\hline Cumulative incidence, $20 \mathrm{y}$ & $2.5-8.0 \%$ & Meta-analyses & 3,18 \\
\hline Cumulative incidence, $30 \mathrm{y}$ & $7.5-18.0 \%$ & Meta-analyses & 3,18 \\
\hline \multicolumn{4}{|l|}{ Extent of inflammation } \\
\hline Pancolitis & SIR: $5.6-14.8$ & Meta-analyses & 3,5 \\
\hline Left-sided colitis & SIR: $2.1-2.8$ & Meta-analyses & 3,5 \\
\hline $\begin{array}{l}\text { Primary sclerosing } \\
\text { cholangitis }\end{array}$ & OR: 4.0 & Meta-analyses & 25 \\
\hline Pseudopolyposis & OR: $2.1-2.5$ & Case-controls & 10,22 \\
\hline Family history of CRC & RR: 2.4-9.2 & Case-controls & 10,22 \\
\hline
\end{tabular}

Abbreviation: CRC, colorectal cancer; IBD, inflammatory bowel disease; SIR, standardized incidence ratio.

Notes: Standardized incidence rates (SIRs) are all in comparison to general population. Odds ratios (OR) and relative risks (RR) are among IBD patients with and without each risk factor.

to 39 with a RR of 2.65 (95\% CI: $1.97-3.56$ ); both were referenced against those diagnosed older than 40 years. ${ }^{8}$ Despite these high relative risks related to age at diagnosis, the absolute risk of CRC was still low. Among those diagnosed between the ages of 0 and 19 , the absolute risk of CRC after 25 years of disease was $1.64 \%$ (95\% CI: $0.25-3.00 \%$ ) and for those diagnosed between 20 and 39 years of age, the absolute risk of CRC after 25 years was $0.80 \%$ (95\% CI: $0.39-1.20 \%$ ). This reported increased risk was also demonstrated in a metaanalysis of CRC risk, where a diagnosis of IBD at a young age $(<30)$ was associated with a fourfold increase in the risk of CRC. ${ }^{18}$ When not adjusting for age of disease onset, two separate studies defined risk of CRC of $0.6 \%$ at 10 years, 2.5 to $5.4 \%$ after 30 years, and 7.5 to $10.8 \%$ after 30 to 40 years of disease. ${ }^{19}$ Multiple studies and systematic reviews have associated the length of affected colon with an increasing risk of CRC: a SIR of 5.6 for pancolitis, 2.1 for segmental colitis, and 1.7 (nonsignificant) for proctitis. ${ }^{20}$ Short segment inflammation of the colon in the setting of $C D$ was not associated with an increased risk of CRC. ${ }^{21}$ The degree of inflammation, as assessed by either endoscopy (odds ratio [OR]: $2.5, p<0.001$ ) or histology (OR 5.1, $p<0.001$ ), is also associated with the risk of neoplasia. ${ }^{22}$ Pseudopolyps, representative of healed severe mucosal damage, and prior severe inflammation double the risk of CRC within the affected region (OR: 2.5 ; $95 \% \mathrm{CI}$ : $1.4-4.6$ ). ${ }^{10} \mathrm{~A}$ family history of CRC independently increases CRC risk two- to threefold in patients with UC (OR: $3.795 \%$ CI: 1.0-13.2). ${ }^{23}$ Finally, primary sclerosing cholangitis (PSC) appears to be a high impact independent risk factor for IBD-CRC. PSC occurs in 3 to $8 \%$ of patients with UC and 1 to $3 \%$ of patients with CD, though nearly 70 to $80 \%$ of patients with PSC have concomitant IBD. ${ }^{24}$ Despite PSC being associated with a milder disease course, the meta-analysis of 11 studies by Soetikno et al concluded that patients with UC-PSC were at increased risk of CRC compared with patients with UC alone (OR: $4.09 ; 95 \% \mathrm{CI}$ : $2.89-5.76){ }^{25}$

\section{The Biology of IBD-Related CRC}

Decades of evidence have demonstrated a clear link between chronic intestinal inflammation and CRC. The development of IBD-related CRC progresses through a sequence from early/indefinite to low-grade dysplasia (LGD), and then to high-grade dysplasia (HGD) prior to conversion to invasive adenocarcinoma. IBD patients' risk of sporadic adenoma development is similar to the general population. However, they are also at risk of nonpolypoid dysplasia within fields of chronic inflammation. Tissue samples from patients with IBD-related colitis demonstrate increased expression of nitric oxygen synthase, increasing the local abundance of reactive oxygen species. ${ }^{26,27}$ This oxidative stress is associated with $p 53$ loss of function mutations, hypermethylation of the MLH1 gene, and microsatellite instability. In fact, deleterious p53 mutations were observed in $6 \%$ of biopsies without dysplasia, $33 \%$ of biopsies with LGD, $63 \%$ with HGD, and $83 \%$ of biopsies containing cancer. ${ }^{28} \mathrm{~A}$ principal mechanistic difference observed is that APC mutations, which occur early in the sporadic adenoma-carcinoma cascade, instead occur late in transition from dysplasia to carcinoma in IBDassociated dysplasia. ${ }^{29}$

Chronic colitis-associated dysplasia may also be associated with aberrations in both innate and adaptive immune responses that are themselves pro-neoplastic. TNF is well described as a key mediator of mucosal inflammation in IBD, but also has a role in carcinogenesis. TNF induces activation of NF-KB in the intestinal epithelium, subsequently upregulating antiapoptotic signals mediated by netrin- 1 and Stat3 (via IL-6). ${ }^{30,31}$ Murine NF-KB knockdown models still developed colitis when exposed to DSS; however, they developed fewer and smaller intestinal tumors. ${ }^{32}$ The adaptive immune response appears to play a role in IBD-related carcinogenesis through the interplay between chronic inflammatory cytokines and the resident intestinal microbiome. Regulatory T-cells (Treg), stimulated by IL-10, dampen intestinal 
inflammation and induce epithelial apoptosis. ${ }^{33}$ However, when exposed to a proinflammatory cytokines, Treg inhibition of inflammation and proapoptotic effects are reduced. ${ }^{34}$ The reduction of IL-10:Treg inflammation inhibition increases Th17 cell cytokine production, specifically IL-6 which induces Stat3 production. ${ }^{35}$ In a systematic review and state-of-the-art commentary, Ullman and Itzkowitz suggest that the global antiapoptotic effects resulting from the inflammatory cytokine milieu may serve to induce resistance against acute epithelial damage. ${ }^{36}$ However, when inflammation persists, the antiapoptotic response in the setting of accumulating genomic damage culminates in mucosal dysplasia. Additionally, the development of dysplasia within chronically damaged de-epithelialized mucosa could also explain the nonpolypoid morphologies often observed in IBD-associated colonic dysplasia.

\section{Dysplasia Detection Methods in IBD}

\section{Dysplasia Terminology}

Both polypoid and nonpolypoid lesions can occur sporadically, but are believed to be more aggressive and rapidly progressive when occurring in a region with presently or previously active colitis. ${ }^{37}$ Confusing nonstandardized terms have been used to communicate the behavior and risk of transformation into carcinoma based on morphology and localized colitis history. Dysplasia-associated lesion or mass (DALM) is typically described as a polypoid-like, often sessile lesion, within an area of current or prior colitis. and was These DALMs were believed to be at high risk for harboring malignancy within the submucosa, often deep to biopsies. The adenoma-like mass (ALM) described a more pedunculated polyp in an area of the colon not previously believed to have been affected by colitis. They have also been called polypoid dysplasia and were felt to have a better prognosis then a DALM. Finally, flat dysplasia described minimally elevated or depressed lesions in the mucosa. Commenting on flat lesions was to communicate the existence of very difficult to visualize dysplasia and raise concern for additional "invisible" dysplasia, often prompting prophylactic colectomy due to the threat of lurking malignancy. The inconsistent and unstandardized terms describing dysplasia in the past (DALM, ALM, flat dysplasia) have been replaced with the Paris endoscopic classification system. ${ }^{38}$ Though itself somewhat cumbersome, it does standardize descriptive criteria of dysplastic lesions in IBD.

\section{White Light Endoscopy with Random Biopsy}

The predilection for nonpolypoid dysplasia in IBD has been appreciated for decades and prompted additional methods to supplant traditional colonoscopy. Standard white light endoscopy (WLE) used in screening programs has been attributed to the documented reduction of incident CRC in the general population. ${ }^{39,40}$ Yet, even when completing surveillance on schedule, an analysis of the SEER database found that the interval risk of CRC 6 to 36 months following colonoscopy was significantly greater in IBD (15.8\%) compared with non-IBD patients $(5.8 \%, p<0.001) .{ }^{41}$ While difference in the biology and natural history of colitis-associated CRC exist difficulty detecting nonpolypoid, often flat lesions, is the most attributable reason for the frequency of missed dysplasia and cancer. To address these so-called invisible lesions, professional societies previously uniformly recommended obtaining random biopsies of the mucosa every $10 \mathrm{~cm}$. Models based on retrospective data reported that greater than 33 biopsies can detect dysplasia with a sensitivity of $90 \% .{ }^{42}$ However, random biopsy samples less than $1 \%$ of the total colon surface area, it is time consuming, costly, and often incompletely performed, raising questions of its practicality and overall utility for CRC detection. ${ }^{43}$ The improved mucosal detail appreciated using highdefinition endoscopic equipment has dramatically improved dysplasia detection in IBD. A retrospective observational study in 357 patients with IBD found high-definition colonoscopy detected over twice as many dysplastic lesions compared with standard definition WLE (RR: 2.2, 95\% CI: 1.1-4.5). ${ }^{44}$ Additional retrospective studies have reported that dysplasia detected on random biopsies was visible in 90 to $94 \%$ of cases using high-definition endoscopic equipment. ${ }^{45}$ of course, the value of a high-quality bowel preparation and slow, careful inspection during colonoscopy withdrawal cannot be overstated.

\section{Chromoendoscopy}

Chromoendoscopy (CE) is an image enhancement technique where methylene blue or indigo carmine dyes are applied during colonoscopy to augment visualization of mucosa detail and topography. CE dyes can be used to enhance the entire colon surface, as well as targeted evaluation of suspicious lesions. A prospective study of 75 patients undergoing IBD CRC surveillance reported improved dysplasia detection with CE (21.3\%) compared with high-definition endoscopy alone $(9.3 \%, p=0.007) .{ }^{46}$ A recent meta-analysis revealed a significantly increased (7\%) yield of dysplasia detection per patient using CE compared with WLE. ${ }^{47}$ The same group reported an absolute difference in dysplasia detection using WLE with random biopsy versus CE with targeted biopsy of 27 versus 44\%, favoring CE. Another meta-analysis, restricted to prospective studies of standard definition WLE versus CE, reported a number needed to treat of 14.3 (95\% CI: 9.7, 30.3) to detect one additional case of dysplasia or cancer with CE. ${ }^{48}$ However, not all evidence has supported the superiority of CE, especially in comparison to high-definition endoscopy. In a Dutch cohort, a group of 401 patients undergoing CE had a dysplasia detection of $11 \%$, compared with $10 \%$ in 772 patients undergoing high-definition endoscopy with targeted and random biopsies $(p=0.80) .{ }^{49,50} \mathrm{CE}$ additionally has practical considerations tempering enthusiasm for wide adoption, including lengthening procedure time by a median of 11 minutes, limited community experience, and the absence of standardized practice and training protocols. ${ }^{47}$

As a result, professional societies differ in their position on the use of CE. Both the National Institute for Health and Care Excellence (NICE) and the European Crohn's and Colitis Organization (ECCO) have recommended the routine use of CE with targeted biopsies in IBD-CRC surveillance in their society guidelines. ${ }^{51,52}$ However, in the United States, the 
American College of Gastroenterology (ACG) and the Crohn's and Colitis Foundation of America (CCFA) have yet to formally endorse $C E$ as the preferred method of CRC surveillance in IBD, recommending its use be an adjunctive method to interrogate suspicious lesions. ${ }^{53}$ The American Gastroenterological Association (AGA) IBD-CRC surveillance guidelines from 2010 also recommend high-quality colonoscopy with random biopsies, focusing on a high-quality visual examination and facilitating an excellent bowel preparation. ${ }^{54}$ Given recent uncertainty among providers for best practices in IBDCRC surveillance, the Surveillance for Colorectal Endoscopic Neoplasia Detection and Management in Inflammatory Bowel Disease Patients: International Consensus Recommendations (SCENIC) was commissioned by the American Society for Gastrointestinal Endoscopy (ASGE) and endorsed by the AGA, but not the ACG or CCFA. ${ }^{55}$ SCENIC endorses the routine use of CE for CRC surveillance in IBD. However, several replies have raised question to the utility of widespread implementation; in the United States The debate over integrating CE into standard practice remains. ${ }^{49,56}$

\section{Additional Techniques for Dysplasia Detection}

Narrow band imaging (NBI) restricts light wavelengths to between 415 and $540 \mathrm{~nm}$ and provides improved visualization of mucosal and submucosal vasculature. Because of its success in identifying dysplasia in the esophagus, NBI has been studied as a method to improve detection of colonic dysplasia. Unfortunately, randomized trials have shown no benefit of NBI over high-definition colonoscopy for colitis-associated dysplasia. ${ }^{57,58}$ Given the absence of any demonstrated benefit, NBI cannot be suggested in place of WLE alone. Confocal laser endomicroscopy (CLE), allowing real-time microscopic evaluation of the colonic mucosa, is an alternative approach for dysplasia detection. In small studies, CLE has been shown to have excellent accuracy compared with matched biopsies for the detection of dysplasia (accuracy: 97.8\%); though not all studies have agreed on the performance of CLE. ${ }^{5,59}$ CLE remains early in clinical development and current inconsistent reliability and high cost compared with traditional biopsy and histology still limit CLE technology to research use. The invasiveness and cost of colonoscopy combined with the remaining potential of missing dysplasia have raised interest in the use of DNA-based stool tests for CRC surveillance in IBD. A casecontrol study matching 19 patients with and 35 patients without colonic dysplasia or cancer found stool markers had sensitivities of $100 \%$ for carcinoma, $100 \%$ for HGD, and $67 \%$ for LGD, all with a specificity of $89 \% .{ }^{60}$ While early in their evaluation, stool markers may serve as an important adjunct to CRC surveillance in IBD. Recent small pilot studies have demonstrated that methylated DNA targets associated with colonic neoplasia can be detected in the stool of IBD patients with adenomas. ${ }^{86}$ A key marker, methylated bone morphogenic protein 3 was present in to the stool of $63 \%$ of lowgrade and $81 \%$ of high-grade dysplasia cases. While these results require replication and verification, stool-based DNA biomarkers for dysplasia may allow for targeted endoscopic surveillance and potentially reduce the frequency for colonoscopy.

\section{Dysplasia Management}

While the detection of dysplasia has not been directly associated with reductions in mortality, several studies support the value of the dysplasia detection prior to the development of CRC. Dysplasia is typically graded as low grade (LGD) or high grade (HGD) based on cytologic features. In the past, the discovery of nonpolypoid colonic dysplasia frequently resulted in recommendations for proctocolectomy. A systematic review using data from the $1980 \mathrm{~s}$ through early 1990 s reported that in 10 of 24 patients with HGD in a nonpolypoid lesion who underwent colectomy, $42 \%$ of patients were found to have synchronous CRC. ${ }^{61}$ In that same study, 15 of 47 patients (32\%) with HGD who did not undergo colectomy ultimately developed CRC. While felt to be lower risk, LGD conferred a ninefold increase of future CRC in a 2007 meta-analysis with a mean follow up of 5.2 years. $^{62}$ Furthermore, of those with LGD undergoing colectomy, $26 \%$ had concurrent CRC and $12 \%$ had HGD identified. However, a vast majority many cases of once "invisible" dysplastic lesions are now detected, and in many cases can be removed, by modern endoscopic methods. As a result, more recent studies report lower progression of LGD and HGD to more advanced dysplasia or neoplasia, likely because of improved endoscopic visualization and resection. ${ }^{63,64}$

Improved confidence in dysplasia visualization has resulted in experienced practitioners more frequently opting for endoscopic removal of dysplasia with close follow-up, as opposed to routinely recommending proctocolectomy. While definitive guidelines have not been established, professional societies have released position statements regarding dysplasia management. ${ }^{52,55}$ When nonpolypoid dysplastic lesions are well visualized with discrete boundaries, endoscopic mucosal or submucosal resection by an experienced provider is an option supported by both the ECCO and SCENIC position statements. Resection site tattooing and sampling biopsies from around the resection site to verify cleared margins are suggested; patients should have a surveillance colonoscopy 3 to 6 months following the resection to evaluate for recurrence. Despite increasing use of curative endoscopic resection, several dysplasia scenarios may still be best served by a total proctocolectomy (-Fig. 1). The presence of LGD in an IBD-PSC patient is associated with a $30 \%$ probability of conversion to HGD or CRC within 1 year and is likely best addressed by colectomy. ${ }^{65}$ In addition, when multifocal dysplasia is discovered, especially on random biopsy without a clearly visualized lesion, many experts will advise colectomy due to concerns of undetected dysplasia or cancer. ${ }^{66}$ Furthermore, overall local experience and endoscopic capabilities, confidence in lesion visualization, additional risk factors (especially family history and PSC), and patient preference all factor into decisions whether or not to pursue proctocolectomy, which remains the most conservative, albeit invasive, treatment strategy. Ultimately, decisions between endoscopic resection with close surveillance and proctocolectomy should be highly individualized. 


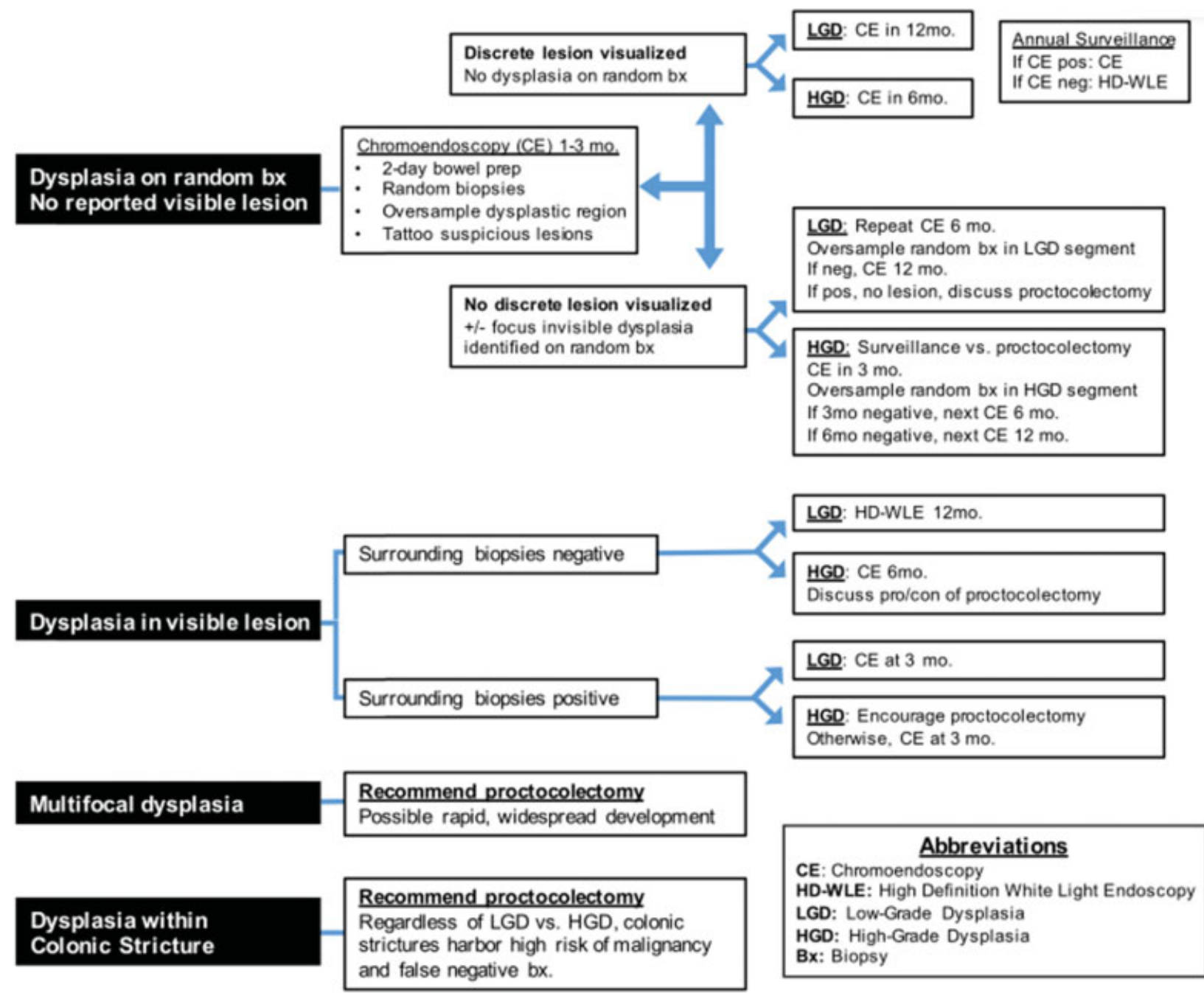

Fig. 1 Proposed decision tree for dysplasia management. Best practices for dysplasia management remain debated. Reductions in the incidence of invisible lesions and improvements in detection methods now allow more opportunities for endoscopic resection with surveillance in efforts to avoid proctocolectomy. Shown is the present algorithm used by the University of Michigan Inflammatory Bowel Disease Program. Surveillance schedule and decisions for endoscopic management versus total proctocolectomy for dysplasia remain highly individualized decisions.

\section{CRC Surveillance Schedule in IBD}

Because of the overall increased risk and earlier age of onset of CRC in IBD, these patients will undergo more frequent colonoscopy, often at an earlier age than the general population. The sensitivity of available techniques for detecting dysplasia, the predilection for difficult to visualize nonpolypoid lesions, and the unpredictable rate of progression from dysplasia to cancer are balanced against the risk and cost of frequent colonoscopy when determining the optimal surveillance schedule. Driving practice patterns in the United States, the AGA and ACG position statements recommend beginning surveillance colonoscopy at 1- to 2-year intervals after 8 to 10 years following IBD symptom onset (-Table 2). ${ }^{53,54}$ Alternatively, the British Society of Gastroenterology (BSG) 2010 CRC surveillance update recommended stratifying the frequency of surveillance colonoscopy to every 1,3 , or 5 years based on high-, intermediate-, or low-risk factors. ${ }^{51}$ In addition, the BSG recommended pancolonic chromoendoscopy in all IBD-CRC surveillance colonoscopies, though random biopsies were an accepted alternative. The BSG surveillance schedule recommendations were later supported by the ECCO European consensus for endoscopy in IBD. ${ }^{52}$ The most recent SCENIC international statement on CRC surveillance in IBD, jointly endorsed by the AGA and ASGE, also endorsed the use of chromoendoscopy but did not comment on the implementation of risk-based surveillance frequency. ${ }^{55}$ Debate continues on the optimal procedure frequency and methods to individualize surveillance schedules that will further reduce morbidity and mortality from CRC in IBD.

The institution of IBD-CRC surveillance programs has resulted in a positive impact on overall outcomes. Patients with IBD participating in CRC surveillance programs have CRCs identified at a significantly earlier stage, translating into better 5 -year survival rates in small studies (100 vs. $74 \%$, $p=0.042) .{ }^{67}$ When examining all-cause mortality, models suggest that compared with the 1 to 4 months of life saved per screening colonoscopy in the general U.S. population, patients with extensive UC in a CRC surveillance program 
Table 2 Summary of guidelines and consensus statements for CRC surveillance in IBD

\begin{tabular}{|c|c|c|c|c|}
\hline Society & Year & $\begin{array}{l}\text { Initiation of } \\
\text { surveillance }\end{array}$ & $\begin{array}{l}\text { Surveillance sche- } \\
\text { dule }\end{array}$ & $\begin{array}{l}\text { Recommended } \\
\text { surveillance method }\end{array}$ \\
\hline AGA (United States) & 2010 & $\begin{array}{l}8-10 \text { y after } \\
\text { symptom onset } \\
\text { PSC-IBD }{ }^{\text {a }} \text { begin at } \\
\text { diagnosis }\end{array}$ & Every $1-20$ y & \\
\hline \multirow{4}{*}{$\begin{array}{l}\text { BSG (United Kingdom } \\
\text { and Ireland) }\end{array}$} & \multirow[t]{4}{*}{2010} & \multirow{4}{*}{$\begin{array}{l}8-10 \text { y after } \\
\text { symptom onset }\end{array}$} & Risk based & \multirow{4}{*}{$\begin{array}{l}\text { Chromoendoscopy } \\
\text { with targeted biopsy } \\
\text { Random biopsy } \\
\text { ( } 4 \text { quadrant) every } \\
10 \mathrm{~cm} \text { if CE expertise } \\
\text { unavailable }\end{array}$} \\
\hline & & & $\begin{array}{l}\text { Low: } 5 \text { y-no } \\
\text { inflammation, or } \\
\text { left-sided colitis, or } \\
\text { CD }<50 \% \text { colon }\end{array}$ & \\
\hline & & & $\begin{array}{l}\text { Intermediate: } \\
3 \text { y-mild } \\
\text { inflammation, or } \\
\text { pseudopolyps, or Fhx } \\
\text { of }>50 \text { CRC }\end{array}$ & \\
\hline & & & $\begin{array}{l}\text { High: } 1 \text { y-moderate } \\
\text { inflammation, or } \\
\text { stricture, OR PSC, or } \\
\text { Fhx of CRC }<50\end{array}$ & \\
\hline \multirow{4}{*}{$\begin{array}{l}\text { ECCO (European } \\
\text { Consensus) }\end{array}$} & \multirow[t]{4}{*}{2013} & \multirow{4}{*}{$\begin{array}{l}6-8 \text { y after symptom } \\
\text { onset }\end{array}$} & Risk based & \multirow{4}{*}{$\begin{array}{l}\text { Chromoendoscopy } \\
\text { with targeted biopsies } \\
\text { and mode of choice } \\
\text { for trained } \\
\text { endoscopists. WLE } \\
\text { with random biopsy } \\
\text { and targeted biopsy } \\
\text { of any lesions is } \\
\text { alternative }\end{array}$} \\
\hline & & & $\begin{array}{l}\text { Risk factors: PSC, } \\
\text { pancolitis, active } \\
\text { inflammation, } \\
\text { pseudopolyps, Fhx of } \\
\text { CRC }\end{array}$ & \\
\hline & & & $\begin{array}{l}\text { Low risk ( } 1-2 \text { Risk } \\
\text { Factors): every } 3-4 \text { y }\end{array}$ & \\
\hline & & & $\begin{array}{l}\text { High risk (3-4 Risk } \\
\text { Factors): every } 1-2 \text { y }\end{array}$ & \\
\hline
\end{tabular}

Abbreviation: AGA, American Gastroenterological Association; BSG, British Society of Gastroenterology; CD, Crohn's disease; CE; chromoendoscopy; CRC, colorectal cancer; Fhx, family history; IBD, inflammatory bowel disease; PSC, primary sclerosing cholangitis; WLE, white light endoscopy.

${ }^{\mathrm{a}}$ All societies recommend surveillance in all patients with IBD-related colitis, except isolated proctitis or CD involving less than 1 segment of the colon.

using colonoscopy gained 14.4 to 60.0 months of life. ${ }^{68}$ However, there have been no studies demonstrating conclusive evidence that CRC surveillance in IBD actually prevents the development of CRC. A Cochrane review did not demonstrate that CRC surveillance in IBD reduces the incidence of CRC, though only two studies met the inclusion criteria of having a control group. ${ }^{69}$ While less robust data, retrospective studies show a reduction in the OR of CRC in patients with IBD participating in surveillance programs. ${ }^{10} \mathrm{~A}$ more recent retrospective study of 6,823 patients with IBD from two tertiary care hospitals in Boston where 154 patients developed CRC found that having a colonoscopy within 6 to 36 months of CRC diagnosis was associated with a lower mortality rate (OR: $0.34 ; 95 \% \mathrm{CI}: 0.12-0.95){ }^{70}$

\section{IBD Therapeutics for CRC prevention}

\section{Aminosalicylates}

Ideally, neoplasia would be completely prevented. Optimal control of inflammation is the most obvious modifiable risk factor for dysplasia development. In addition, IBD therapies may have chemopreventive properties independent of inflammation suppression. The aminosalicylates (5-ASA) are the most studied therapeutic class for chemoprevention of CRC in IBD. The 5-ASA class increases mucosal expression of PPAR- $\gamma$ which modulates the $\beta$-catenin oncogenic pathway and also inhibits tumor angiogenesis mediated by COX-2. ${ }^{71} \mathrm{~A}$ meta-analysis of 1,932 patients in 2001 reported that 5-ASAs were protective against both CRC and dysplasia (OR: 0.51, 95\% CI: 0.38-0.69). ${ }^{16}$ These findings resulted in the AGA endorsing the use of 5-ASA maintenance therapy, even in the setting of controlled mucosal inflammation, for CRC chemoprevention. ${ }^{54}$ However, follow-up population-based studies performed by several groups, adjusting for critical CRC risk factors failed to confirm the chemopreventive benefit of 5-ASA agents. Examining 8,700 patients with IBD in the Manitoba IBD population-based cohort, Bernstein and colleagues found 5-ASAs rendered no protective benefit against CRC (OR: 1.04, 95\% CI: 0.67-1.62). ${ }^{72}$ A more recent metaanalysis also failed to demonstrate a protective benefit against CRC (OR: 0.95, 95\% CI: $0.66-1.38) .{ }^{73}$ Although controversial, contemporary data do not conclusively support a 
chemopreventive effect of 5-ASA therapies independent of inflammation control.

\section{Thiopurines}

The use of thiopurine has been shown to be protective against the development of both HGD and CRC. In the CESAME national French prospective observational cohort study, the use of thiopurine was associated with a reduced hazard of CRC among those with longstanding extensive colitis (HR: 0.28 , $95 \%$ CI: 0.1, 0.9). ${ }^{6}$ These results were corroborated by a similar study of IBD patients in the Netherlands. ${ }^{74}$ Interestingly, when examining all IBD patients regardless of duration and extent of colitis, thiopurines rendered no significant protection from CRC or dysplasia. A meta-analysis showed a nonsignificant trend of reduction in the relative risk of CRC or dysplasia of 0.71 (95\% CI: 0.50, 1.03) among thiopurine users. ${ }^{75}$ Additionally, in a population-based Dutch study of 43,969 patients with IBD, the use of thiopurine was not associated with reduced risk of $\mathrm{CRC}^{76}$ Similar to the principal limitation of 5-ASA chemoprevention studies, the lack of control for mucosal inflammation makes it difficult to determine whether thiopurines have a chemopreventive effect independent of inflammation control, if any impact exists at all.

\section{Biologics}

Anti-TNF therapeutics also have conflicting results in studies of CRC prevention. In contrast to 5-ASA and thiopurine agents, some evidence exists for anti-TNF therapies being associated with enhancing tumor growth based on animal models of experimental colitis. ${ }^{77}$ A small case-control study of 173 patients with IBD-related CRC and 393 non-CRC IBD controls between 1990 and 2006 demonstrated a strong protective effect from anti-TNF (OR: 0.09, 95\% CI: $0.01-$ $0.68)$, which was not observed in population-based series $(\mathrm{RR}=1.06 ; 95 \% \mathrm{CI}: 0.33-3.40) .{ }^{78}$ These population-based data, combined with meta-analysis of case-control and cohort studies, appear, at the least, to suggest that antiTNF therapy does not increase the risk of CRC, and it likely exerts a chemopreventive effect through control of mucosal inflammation. ${ }^{79}$ Vedolizumab, an anti-adhesion biologic therapy approved for UC and CD in 2014, reduces intestinal inflammation by retarding leukocyte migration. While a systematic review and meta-analysis did not reveal an increase in any malignancies, there is insufficient experience to make statements on its impact on CRC incidence in IBD. Overall, the ability of improved medications to control inflammation, rather than a direct anticancer effect, appears to be the cause of reductions in CRC in IBD over time.

\section{IBD Therapeutics and the Risk of Malignancy Progression or Recurrence}

Decisions on the medical management of IBD in the setting of active or recent cancer are challenging and there are little reliable data on this topic. Current practice is most influenced by extrapolation from epidemiologic data, principally from the organ-transplant literature and our understanding of therapeutic mechanisms of action. Observational studies in Denmark have shown that IBD patients with breast cancer have higher mortality than non-IBD patients. ${ }^{80}$ Most providers significantly reduce use of immunosuppressant medication and increase use of corticosteroid following a cancer diagnosis in the setting of IBD. ${ }^{81,82}$ Thiopurines are extensively used in the organ-transplant population and have been linked to incident and recurrent lymphoproliferative disease. ${ }^{83}$ These data have discouraged use of thiopurine in the setting of active malignancy and in situations, where surgical removal of malignant tissue (locally or distant metastasis) is difficult to confirm. As discussed previously, TNF has been demonstrated to both inhibit (via apoptosis) and promote (via NF-kB) neoplasia, making it difficult to predict the impact of anti-TNF therapy on malignancy. Several groups have examined the effect of anti-TNF treatments, alone or in combination with chemotherapy, in patients with concomitant solid tumors. ${ }^{84,85}$ While these small studies were short and likely biased by provider judgement on candidacy for anti-TNF therapy, no clear changes in overall mortality or cancer progression were observed in those exposed to antiTNF therapy. The impact of vedolizumab on the progression, diagnosis stage, and recurrence of CRC is unknown. Although not well studied, no deleterious impact of methotrexate, oral or rectal 5-ASA therapies, or enteral-specific steroids has been observed.

Considering the lack of evidence, IBD treatment decisions in the setting of active CRC are individualized and should consider tumor stage, severity of IBD, and the malignancy management plan. Upon CRC diagnosis, our group will discontinue use of thiopurine and if possible halt anti-TNF and antiintegrin treatments as well; we will not interrupt methotrexate or 5-ASA therapies. Should IBD symptoms become burdensome pending surgical management, we sequentially step up therapeutic intensity, beginning by maximizing oral and rectal 5-ASA therapies, then adding intestine-localized rectal and oral corticosteroids (budesonide) or systemic steroids (prednisone) if needed. Following surgical resection, in the setting of early-stage tumors without evidence of local or distant metastasis, we will delay resumption of anti-TNF therapy until either the return of moderate objective inflammation or symptoms that are unable to be mitigated by non-immunosuppressive therapies. While thiopurines can be used following surgical resection of localized cancer, we generally defer their use and preferentially use anti-TNF therapy when 5-ASAs are insufficient.

\section{References}

1 Wanders LK, Dekker E, Pullens B, Bassett P, Travis SPL, East JE. Cancer risk after resection of polypoid dysplasia in patients with longstanding ulcerative colitis: a meta-analysis. Clin Gastroenterol Hepatol 2014;12(05):756-764

2 de Dombal FT. Ulcerative colitis. Epidemiology and aetiology, course and prognosis. BMJ 1971;1(5750):649-650

3 Eaden JA, Abrams KR, Mayberry JF. The risk of colorectal cancer in ulcerative colitis: a meta-analysis. Gut 2001;48(04):526-535

4 Bernstein CN, Blanchard JF, Kliewer E, Wajda A. Cancer risk in patients with inflammatory bowel disease: a population-based study. Cancer 2001;91(04):854-862 
5 Söderlund S, Brandt L, Lapidus A, et al. Decreasing time-trends of colorectal cancer in a large cohort of patients with inflammatory bowel disease. Gastroenterology 2009;136(05):1561-1567, quiz 1818-1819

6 Beaugerie L, Svrcek M, Seksik P, et al; CESAME Study Group. Risk of colorectal high-grade dysplasia and cancer in a prospective observational cohort of patients with inflammatory bowel disease. Gastroenterology 2013;145(01):166-175.e8

7 Jess T, Loftus EV Jr, Velayos FS, et al. Risk factors for colorectal neoplasia in inflammatory bowel disease: a nested case-control study from Copenhagen county, Denmark and Olmsted county, Minnesota. Am J Gastroenterol 2007;102(04):829-836

8 Jess T, Simonsen J, Jørgensen KT, Pedersen BV, Nielsen NM, Frisch M. Decreasing risk of colorectal cancer in patients with inflammatory bowel disease over 30 years. Gastroenterology 2012; 143(02):375-81.e1, quiz e13-e14

9 Jess T, Horváth-Puhó E, Fallingborg J, Rasmussen HH, Jacobsen BA. Cancer risk in inflammatory bowel disease according to patient phenotype and treatment: a Danish population-based cohort study. Am J Gastroenterol 2013;108(12):1869-1876

10 Velayos FS, Loftus EV Jr, Jess T, et al. Predictive and protective factors associated with colorectal cancer in ulcerative colitis: a case-control study. Gastroenterology 2006;130(07):1941-1949

11 Andersen NN, Jess T. Has the risk of colorectal cancer in inflammatory bowel disease decreased? World J Gastroenterol 2013; 19(43):7561-7568

12 Lutgens MW, van Oijen MG, van der Heijden GJ, Vleggaar FP, Siersema PD, Oldenburg B. Declining risk of colorectal cancer in inflammatory bowel disease: an updated meta-analysis of population-based cohort studies. Inflamm Bowel Dis 2013;19(04):789-799

13 Jess T, Rungoe C, Peyrin-Biroulet L. Risk of colorectal cancer in patients with ulcerative colitis: a meta-analysis of populationbased cohort studies. Clin Gastroenterol Hepatol 2012;10(06): 639-645

14 Winther KV, Jess T, Langholz E, Munkholm P, Binder V. Long-term risk of cancer in ulcerative colitis: a population-based cohort study from Copenhagen County. Clin Gastroenterol Hepatol 2004; 2(12):1088-1095

15 Canavan C, Abrams KR, Mayberry J. Meta-analysis: colorectal and small bowel cancer risk in patients with Crohn's disease. Aliment Pharmacol Ther 2006;23(08):1097-1104

16 Herrinton LJ, Liu L, Levin TR, Allison JE, Lewis JD, Velayos F. Incidence and mortality of colorectal adenocarcinoma in persons with inflammatory bowel disease from 1998 to 2010. Gastroenterology 2012;143(02):382-389

17 Fumery M, Pineton de Chambrun G, Stefanescu C, et al. Detection of dysplasia or cancer in $3.5 \%$ of patients with inflammatory bowel disease and colonic strictures. Clin Gastroenterol Hepatol 2015;13(10):1770-1775

18 Lakatos PL, Lakatos L. Risk for colorectal cancer in ulcerative colitis: changes, causes and management strategies. World J Gastroenterol 2008;14(25):3937-3947

19 Rutter MD, Saunders BP, Wilkinson KH, et al. Thirty-year analysis of a colonoscopic surveillance program for neoplasia in ulcerative colitis. Gastroenterology 2006;130(04):1030-1038

20 Jess T, Riis L, Vind I, et al. Changes in clinical characteristics, course, and prognosis of inflammatory bowel disease during the last 5 decades: a population-based study from Copenhagen, Denmark. Inflamm Bowel Dis 2007;13(04):481-489

21 Itzkowitz SH, Present DH; Crohn's and Colitis Foundation of America Colon Cancer in IBD Study Group. Inflamm Bowel Dis 2005; 11(03):314-321

22 Rutter MD, Saunders BP, Wilkinson KH, et al. Cancer surveillance in longstanding ulcerative colitis: endoscopic appearances help predict cancer risk. Gut 2004;53(12):1813-1816

23 Askling J, Dickman PW, Karlén P, et al. Family history as a risk factor for colorectal cancer in inflammatory bowel disease. Gastroenterology 2001;120(06):1356-1362
24 Molodecky NA, Soon IS, Rabi DM, et al. Increasing incidence and prevalence of the inflammatory bowel diseases with time, based on systematic review. Gastroenterology 2012;142(01):46-54. e42, quiz e30

25 Soetikno RM, Lin OS, Heidenreich PA, Young HS, Blackstone MO. Increased risk of colorectal neoplasia in patients with primary sclerosing cholangitis and ulcerative colitis: a meta-analysis. Gastrointest Endosc 2002;56(01):48-54

26 Hofseth LJ, Saito S, Hussain SP, et al. Nitric oxide-induced cellular stress and p53 activation in chronic inflammation. Proc Natl Acad Sci U S A 2003;100(01):143-148

27 Xavier RJ, Podolsky DK. Unravelling the pathogenesis of inflammatory bowel disease. Nature 2007;448(7152):427-434

28 Burmer GC, Rabinovitch PS, Haggitt RC, et al. Neoplastic progression in ulcerative colitis: histology, DNA content, and loss of a p53 allele. Gastroenterology 1992;103(05):1602-1610

29 Aust DE, Terdiman JP, Willenbucher RF, et al. The APC/betacatenin pathway in ulcerative colitis-related colorectal carcinomas: a mutational analysis. Cancer 2002;94(05):1421-1427

30 Paradisi A, Maisse C, Coissieux M-M, et al. Netrin-1 up-regulation in inflammatory bowel diseases is required for colorectal cancer progression. Proc Natl Acad Sci U S A 2009;106(40): 17146-17151

31 Becker C, Fantini MC, Schramm C, et al. TGF-beta suppresses tumor progression in colon cancer by inhibition of IL- 6 transsignaling. Immunity 2004;21(04):491-501

32 Greten FR, Eckmann L, Greten TF, et al. IKKbeta links inflammation and tumorigenesis in a mouse model of colitis-associated cancer. Cell 2004;118(03):285-296

33 Pagès F, Berger A, Camus $\mathrm{M}$, et al. Effector memory $\mathrm{T}$ cells, early metastasis, and survival in colorectal cancer. N Engl J Med 2005; 353(25):2654-2666

34 Erdman SE, Poutahidis T. Cancer inflammation and regulatory T cells. Int J Cancer 2010;127(04):768-779

35 Deng L, Zhou J-F, Sellers RS, et al. A novel mouse model of inflammatory bowel disease links mammalian target of rapamycin-dependent hyperproliferation of colonic epithelium to inflammation-associated tumorigenesis. Am J Pathol 2010; 176(02):952-967

36 Ullman TA, Itzkowitz SH. Intestinal inflammation and cancer. Gastroenterology 2011;140(06):1807-1816

37 Vieth M, Behrens H, Stolte M. Sporadic adenoma in ulcerative colitis: endoscopic resection is an adequate treatment. Gut 2006; 55(08):1151-1155

38 Gupta S. Trouble in Paris (classification): polyp morphology is in the eye of the beholder. Am J Gastroenterol 2015;110(01): 188-191

39 Brenner H, Haug U, Arndt V, Stegmaier C, Altenhofen L, Hoffmeister $\mathrm{M}$. Low risk of colorectal cancer and advanced adenomas more than 10 years after negative colonoscopy. Gastroenterology 2010;138(03):870-876

40 Schoen RE, Pinsky PF, Weissfeld JL, et al; PLCO Project Team. Colorectal-cancer incidence and mortality with screening flexible sigmoidoscopy. N Engl J Med 2012;366(25):2345-2357

41 Wang YR, Cangemi JR, Loftus EV Jr, Picco MF. Rate of early/missed colorectal cancers after colonoscopy in older patients with or without inflammatory bowel disease in the United States. Am J Gastroenterol 2013;108(03):444-449

42 Rubin CE, Haggitt RC, Burmer GC, et al. DNA aneuploidy in colonic biopsies predicts future development of dysplasia in ulcerative colitis. Gastroenterology 1992;103(05):1611-1620

43 Iacucci M, Uraoka T, Fort Gasia M, Yahagi N. Novel diagnostic and therapeutic techniques for surveillance of dysplasia in patients with inflammatory bowel disease. Can J Gastroenterol Hepatol 2014;28(07):361-370

44 Efthymiou M, Allen PB, Taylor ACF, et al. Chromoendoscopy versus narrow band imaging for colonic surveillance in inflammatory bowel disease. Inflamm Bowel Dis 2013;19(10):2132-2138 
45 Subramanian V, Ramappa V, Telakis E, et al. Comparison of high definition with standard white light endoscopy for detection of dysplastic lesions during surveillance colonoscopy in patients with colonic inflammatory bowel disease. Inflamm Bowel Dis 2013;19(02):350-355

46 Picco MF, Pasha S, Leighton JA, et al. Procedure time and the determination of polypoid abnormalities with experience: implementation of a chromoendoscopy program for surveillance colonoscopy for ulcerative colitis. Inflamm Bowel Dis 2013;19(09):1913-1920

$47 \mathrm{Wu} \mathrm{L}$, Li P, Wu J, Cao Y, Gao F. The diagnostic accuracy of chromoendoscopy for dysplasia in ulcerative colitis: meta-analysis of six randomized controlled trials. Colorectal Dis 2012; 14(04):416-420

48 Konijeti GG, Shrime MG, Ananthakrishnan AN, Chan AT. Costeffectiveness analysis of chromoendoscopy for colorectal cancer surveillance in patients with ulcerative colitis. Gastrointest Endosc 2014;79(03):455-465

49 Mooiweer E, van der Meulen-de Jong AE, Ponsioen CY, et al. Chromoendoscopy for surveillance in inflammatory bowel disease does not increase neoplasia detection compared with conventional colonoscopy with random biopsies: results from a large retrospective study. Am J Gastroenterol 2015;110(07): 1014-1021

50 van den Broek FJ, Stokkers PC, Reitsma JB, et al. Random biopsies taken during colonoscopic surveillance of patients with longstanding ulcerative colitis: low yield and absence of clinical consequences. Am J Gastroenterol 2014;109(05):715-722

51 Cairns SR, Scholefield JH, Steele RJ, et al; British Society of Gastroenterology; Association of Coloproctology for Great Britain and Ireland. Guidelines for colorectal cancer screening and surveillance in moderate and high risk groups (update from 2002). Gut 2010;59(05):666-689

52 Annese V, Daperno M, Rutter MD, et al. European evidence based consensus for endoscopy in inflammatory bowel disease.J Crohns Colitis 2013;7(12):982-1018

53 Kornbluth A, Sachar DB; Practice Parameters Committee of the American College of Gastroenterology. Ulcerative colitis practice guidelines in adults: American College of Gastroenterology, Practice Parameters Committee. Am J Gastroenterol 2010;105(03):501-523, quiz 524

54 Farraye FA, Odze RD, Eaden J, et al; AGA Institute Medical Position Panel on Diagnosis and Management of Colorectal Neoplasia in Inflammatory Bowel Disease. AGA medical position statement on the diagnosis and management of colorectal neoplasia in inflammatory bowel disease. Gastroenterology 2010;138(02):738-745

55 Laine L, Kaltenbach T, Barkun A, McQuaid KR, Subramanian V, Soetikno R; SCENIC Guideline Development Panel. SCENIC international consensus statement on surveillance and management of dysplasia in inflammatory bowel disease. Gastrointest Endosc 2015;81(03):489-501.e26

56 Marion JF, Waye JD, Israel Y, et al; Chromoendoscopy Study Group at Mount Sinai School of Medicine. Chromoendoscopy is more effective than standard colonoscopy in detecting dysplasia during long-term surveillance of patients with colitis. Clin Gastroenterol Hepatol 2016;14(05):713-719

57 Ignjatovic A, East JE, Subramanian V, et al. Narrow band imaging for detection of dysplasia in colitis: a randomized controlled trial. Am J Gastroenterol 2012;107(06):885-890

58 van den Broek FJ, Fockens P, van Eeden S, et al. Narrow-band imaging versus high-definition endoscopy for the diagnosis of neoplasia in ulcerative colitis. Endoscopy 2011;43(02):108-115

59 Kiesslich R, Goetz M, Angus EM, et al. Identification of epithelial gaps in human small and large intestine by confocal endomicroscopy. Gastroenterology 2007;133(06):1769-1778

60 Kisiel JB, Yab TC, Nazer Hussain FT, et al. Stool DNA testing for the detection of colorectal neoplasia in patients with inflammatory bowel disease. Aliment Pharmacol Ther 2013;37(05):546-554
61 Bernstein CN, Shanahan F, Weinstein WM. Are we telling patients the truth about surveillance colonoscopy in ulcerative colitis? Lancet 1994;343(8889):71-74

62 Thomas T, Abrams KA, Robinson RJ, Mayberry JF. Meta-analysis: cancer risk of low-grade dysplasia in chronic ulcerative colitis. Aliment Pharmacol Ther 2007;25(06):657-668

63 Navaneethan U, Jegadeesan R, Gutierrez NG, et al. Progression of low-grade dysplasia to advanced neoplasia based on the location and morphology of dysplasia in ulcerative colitis patients with extensive colitis under colonoscopic surveillance. J Crohn's Colitis 2013;7(12):e684-e691

64 Murphy J, Kalkbrenner KA, Pemberton JH, et al. Dysplasia in ulcerative colitis as a predictor of unsuspected synchronous colorectal cancer. Dis Colon Rectum 2014;57(08):993-998

65 Venkatesh PG, Jegadeesan R, Gutierrez NG, Sanaka MR, Navaneethan $U$. Natural history of low grade dysplasia in patients with primary sclerosing cholangitis and ulcerative colitis. J Crohn's Colitis 2013;7(12):968-973

66 Coviello LC, Stein SL. Surgical management of nonpolypoid colorectal lesions and strictures in colonic inflammatory bowel disease. Gastrointest Endosc Clin N Am 2014;24(03):447-454

67 Lutgens MW, Oldenburg B, Siersema PD, et al. Colonoscopic surveillance improves survival after colorectal cancer diagnosis in inflammatory bowel disease. Br J Cancer 2009;101(10): 1671-1675

68 Provenzale D, Wong JB, Onken JE, Lipscomb J. Performing a costeffectiveness analysis: surveillance of patients with ulcerative colitis. Am J Gastroenterol 1998;93(06):872-880

69 Collins PD, Mpofu C, Watson AJ, Rhodes JM. Strategies for detecting colon cancer and/or dysplasia in patients with inflammatory bowel disease. Cochrane Database Syst Rev 2006;(02):CD000279

70 Ananthakrishnan AN, Cagan A, Cai T, et al. Colonoscopy is associated with a reduced risk for colon cancer and mortality in patients with inflammatory bowel diseases. Clin Gastroenterol Hepatol 2015;13(02):322-329.e1

71 Subramanian V, Logan RF. Chemoprevention of colorectal cancer in inflammatory bowel disease. Best Pract Res Clin Gastroenterol 2011;25(4-5):593-606

72 Bernstein CN, Nugent Z, Blanchard JF. 5-aminosalicylate is not chemoprophylactic for colorectal cancer in IBD: a population based study. Am J Gastroenterol 2011;106(04):731-736

73 Nguyen GC, Gulamhusein A, Bernstein CN. 5-aminosalicylic acid is not protective against colorectal cancer in inflammatory bowel disease: a meta-analysis of non-referral populations. Am J Gastroenterol 2012;107(09):1298-1304, quiz 1297, 1305

74 van Schaik FDM, van Oijen MGH, Smeets HM, van der Heijden GJMG, Siersema PD, Oldenburg B. Thiopurines prevent advanced colorectal neoplasia in patients with inflammatory bowel disease. Gut 2012;61(02):235-240

75 Gong J, Zhu L, Guo Z, et al. Use of thiopurines and risk of colorectal neoplasia in patients with inflammatory bowel diseases: a metaanalysis. PLoS One 2013;8(11):e81487

76 Pasternak B, Svanström H, Schmiegelow K, Jess T, Hviid A. Use of azathioprine and the risk of cancer in inflammatory bowel disease. Am J Epidemiol 2013;177(11):1296-1305

77 Onizawa M, Nagaishi T, Kanai T, et al. Signaling pathway via TNFalpha/NF-kappaB in intestinal epithelial cells may be directly involved in colitis-associated carcinogenesis. Am J Physiol Gastrointest Liver Physiol 2009;296(04):G850-G859

78 Baars JE, Kuipers EJ, van Haastert M, Nicolaï JJ, Poen AC, van der Woude CJ. Age at diagnosis of inflammatory bowel disease influences early development of colorectal cancer in inflammatory bowel disease patients: a nationwide, long-term survey. J Gastroenterol 2012;47(12):1308-1322

79 Osterman MT, Sandborn WJ, Colombel JF, et al. Increased risk of malignancy with adalimumab combination therapy, compared with monotherapy, for Crohn's disease. Gastroenterology 2014; 146(04):941-949 
80 Søgaard KK, Cronin-Fenton DP, Pedersen L, Sørensen HT, Lash TL. Survival in Danish patients with breast cancer and inflammatory bowel disease: a nationwide cohort study. Inflamm Bowel Dis 2008;14(04):519-525

81 Guerra I, Bermejo F. Management of inflammatory bowel disease in poor responders to infliximab. Clin Exp Gastroenterol 2014; 7:359-367

82 Raaschou P, Simard JF, Neovius M, Askling J; Anti-Rheumatic Therapy in Sweden Study Group. Does cancer that occurs during or after anti-tumor necrosis factor therapy have a worse prognosis? A national assessment of overall and site-specific cancer survival in rheumatoid arthritis patients treated with biologic agents. Arthritis Rheum 2011;63(07):1812-1822

83 Jess T, Lopez A, Andersson M, Beaugerie L, Peyrin-Biroulet L. Thiopurines and risk of colorectal neoplasia in patients with inflammatory bowel disease: a meta-analysis. Clin Gastroenterol Hepatol 2014;12(11):1793-1800.e1

84 Brown ER, Charles KA, Hoare SA, et al. A clinical study assessing the tolerability and biological effects of infliximab, a TNF-alpha inhibitor, in patients with advanced cancer. Ann Oncol 2008; 19(07):1340-1346

85 Jatoi A, Ritter HL, Dueck A, et al. A placebo-controlled, double-blind trial of infliximab for cancer-associated weight loss in elderly and/or poor performance non-small cell lung cancer patients (N01C9). Lung Cancer 2010;68(02): 234-239

86 Johnson DH, Taylor WR, Aboelsoud MM, et al. DNA methylation and mutation of small colonic neoplasms in ulcerative colitis and Crohn's colitis: Implications for Surveillance. Inflamm Bowel Dis 2016;22(07):1559-1567 